BMJ Open Sport \& Exercise Medicine

\title{
Tackle technique knowledge alone does not translate to proper tackle technique execution in training
}

\author{
Steve den Hollander (i) ,1,2,3 Mike Lambert, ${ }^{1,3}$ Ben Jones, ${ }^{1,4,5,6,7}$ \\ Sharief Hendricks (1D) $1,3,4$
}

\begin{abstract}
To cite: den Hollander S, Lambert M, Jones B, et al. Tackle technique knowledge alone does not translate to proper tackle technique execution in training. BMJ Open Sport \& Exercise Medicine 2021;7:e001011. doi:10.1136/ bmjsem-2020-001011

- Additional material is published online only. To view, please visit the journal online (http://dx.doi.org/10.1136/ bmjsem-2020-001011).
\end{abstract}

Accepted 22 February 2021
Check for updates

C Author(s) (or their employer(s)) 2021. Re-use permitted under CC BY-NC. No commercial re-use. See rights and permissions. Published by BMJ.

For numbered affiliations see end of article.

Correspondence to Dr Sharief Hendricks; sharief.hendricks01@gmail.com

\section{ABSTRACT}

Objectives Effective tackle technique is associated with reduced injury risks and improved performance in contact. Injury prevention programmes aim to provide players with knowledge of effective technique. However, little is known of the impact of this knowledge on a player's technique in the tackle. This study aimed to determine the association between knowledge of proper tackle technique and tackle technique proficiency in training.

Methods Fifty-three rugby union players participated in a tackle contact drill and, thereafter, completed a questionnaire. The drill was filmed, and the players' tackle and ball-carry technique were assessed using standardised technical proficiency. In the questionnaire, the players were asked to rate the importance of each tackle and ball-carry technique on a 5-point Likert scale, for both injury prevention and performance tackle outcomes. Linear regression was performed to assess the relationship between the knowledge of the importance of proper tackle technique and tackle technique proficiency during the drill. Results No association was found between players' knowledge of the importance of proper technique and tackle contact technique in training for both injury prevention and performance.

Conclusion The lack of association between players' knowledge and actual tackle contact technique reveals the gap between the knowledge of safe and effective techniques and the knowledge of how to execute the said techniques.

\section{INTRODUCTION}

In rugby union, the tackle is the most frequently occurring contact event and carries the greatest risk of causing injury. ${ }^{1-3}$ For example, in youth rugby union, a tacklerelated injury occurs every 37 playing hours. ${ }^{4}$ One of the major risk factors for sports injuries is technique. ${ }^{5}$ For the tackle specifically, technique has been shown to reduce the risk of injury for both the ball carrier and the tackler. ${ }^{46}$ Proper technique has similarly been shown to increase the likelihood of success in the tackle. ${ }^{78}$ As such, national injury prevention programmes aim to provide coaches, trainers and players with knowledge of proper tackle technique. ${ }^{9}$ For injury prevention

\section{Key messages}

- High awareness of importance of tackle and ballcarry technique to reduce tackle-related injuries in academy rugby players.

- High awareness of importance of tackle and ballcarry technique to win the tackle contest in academy rugby players.

- The players' awareness of safe and effective technique did not relate to their technique proficiency in a contact training drill.

strategies like these to work, the performance benefits of proper technique in the tackle are also advocated. ${ }^{10}$ For example, 'safe technique is also effective technique'. ${ }^{11} 12$

Knowledge of technical skill can be described as either declarative or procedural. $^{13}$ Declarative knowledge refers to knowledge that is factual. ${ }^{13}$ It emphasises what to do to perform a skill. ${ }^{14}$ Procedural knowledge refers to the knowledge of how to perform a skill. ${ }^{13}{ }^{14}$ Acquiring declarative knowledge is often described as the first stage of learning. ${ }^{13}$ This knowledge can then be developed into procedural knowledge. ${ }^{13}$ For example, when learning to drive a car, the first step is to learn the actions for operating a car (declarative knowledge). Through practising these actions over multiple occasions, the processes (using the clutch, checking mirrors and so on) are internalised until they become habitual and can be performed without thinking about the instructions (procedural knowledge). ${ }^{15}$

The knowledge provided through the injury prevention programmes to rugby union stakeholders (coaches, trainers and players) can be described as declarative. Rugby union stakeholders are provided with technical instructions on how to tackle in a safe and effective manner. ${ }^{11}$ Training is the environment where athletes prepare for the demands of competition; therefore, these technical instructions are focused on 
developing players' procedural knowledge of proper technique during training. In South Africa for example, the dissemination of declarative knowledge to rugby union stakeholders seems to be effective, as both players and coaches have reported a high level of awareness of the importance of proper technique to improve performance and reduce injury risks. ${ }^{16-18}$ However, whether declarative knowledge has an impact on players' actions in the tackle contest, in training or matches, is yet to be investigated. Therefore, the purpose of this study was to describe the relationship between knowledge and behaviours in the tackle contest, by comparing players' knowledge of the importance of tackle technique with their tackle technique proficiency, in a tackle training drill.

\section{METHODS}

\section{Participants}

Fifty-three South African academy-level male rugby union players participated in this study ( 25 forwards and 28 backline players). All the players were free from injury and had played rugby union for at least one calendar year. All procedures were approved by the designated university's human research ethics committee (HREC778/2017), and informed consent was obtained from the players prior to them taking part in the study.

\section{Study design}

A cross-sectional design was used to compare rugby union players' knowledge of the importance of technique for injury prevention and performance in the tackle and their tackle technique proficiency. The players' proficiency in tackle and ball-carry technique were recorded in a two-on-two contact drill and assessed retrospectively using standardised tackle and ball-carry technical criteria. ${ }^{46}$ The tackle drill was designed to have a high degree of ecological validity and representativeness. That is, it should provide athletes with relevant affordances and perception-couplings, facilitate the integration of motor processes (ie, techniques) with perceptual-cognitive components (decision-making and tactical awareness), and have action fidelity (the skills and actions performed in training should be able to easily transfer to competition).$^{2021}$ To meet these criteria, the drill included a phase of play before the tackle. It was performed in the corner of a rugby field at the point where the touch-line and the try-line meets, with the ball carrier aiming to score the try and the tackler aiming to prevent the try from being scored. Furthermore, studies using this tackle drill have shown encouraging construct validity by differentiating between levels of play ${ }^{22-24}$ and have been associated with match performance outcomes. ${ }^{25-27}$

Players' knowledge on the tackle were measured through a tackle questionnaire. The questionnaire required the players to rate the importance of each tackle and ball-carry technical criterion (on the standardised technical criteria lists) for performance and injury prevention using a 5-point Likert scale.

\section{Technique assessment}

The two-on-two contact training drill was used to assess the tackle proficiency of the players. Before testing, the players were warmed up and familiarised with the drill. The drill has been described in detail elsewhere. ${ }^{24}$ In brief, the drill started with a simulated ruck, where the ball was passed, via the first attacker, to the ball carrier. The ball carrier then advanced the ball forward in the direction of the tackler. The ball carrier was instructed to 'score the try' and the tackler to prevent the ball carrier from scoring the try using safe and effective tackle technique. The first defender and the first attacker were instructed not to assist in the tackle, but, after the completion of the tackle, to form a ruck. The drill was performed in the corner of a rugby union field. The drill was filmed, and the players' proficiency in tackle and ball-carry technique proficiency were assessed retrospectively using standardised tackle and ball-carry technical criteria. ${ }^{4619}$ The footage of the ruck was not analysed in this study. The first author $(\mathrm{SdH})$ recorded and analysed all the tackle events. The players were awarded 1 point for each criterion they performed and 0 point if they failed to perform the criterion. The number of criteria performed were totalled to provide a score (arbitrary units) for each tackle and ball-carry. ${ }^{24}{ }^{28}$ Each player performed four tackles and four ball-carries, with the players rotating between roles in the drill. The total scores were averaged to calculate the tackle proficiency and ball-carry proficiency score for each player.

\section{Questionnaire}

After completing the contact drill, the players were sent an electronic questionnaire on their knowledge on the tackle situation. The questionnaire, modelled on previous research, ${ }^{16-18} 2129$ consisted of 10 questions related to training and 5 questions related to matches. Questions related to importance and behaviours consisted of a question and a 5-point ordinal Likert scale. Importance of an item was rated on the following scale: (1) not important at all, (2) not too important, (3) undecided, (4) somewhat important, (5) very important. ${ }^{30}$ The quantity of behaviours was rated on a scale of (1) not at all, (2) a little, (3) a fair amount, (4) much, (5) very much. ${ }^{30}$ If a player was not familiar with any of the techniques listed in questions 6 and 7, they had the option of answering not familiar (NF). The questionnaire was developed on Google Forms (online supplemental appendix 1). Only the responses to questions 6 and 7-where players ranked the importance of tackle or ball-carry technique for winning the contest and preventing injuries-were analysed in this study. The Likert scale responses to these questions (1-5) were averaged to provide an overall score for how important the player found tackle technique or ball-carry technique for performance and injury prevention (no players selected $\mathrm{NF}$ as a response).

\section{Public involvement in research}

The public was not involved in the design of this study. However, in previous studies, a panel of rugby coaches, 
sports scientists and rugby administrators were consulted for the development of the questionnaire ${ }^{17}$ and the standardised technical criteria used in this study. ${ }^{6}$

\section{Statistical analysis}

A Spearman's rank correlation analysis was done to assess the effect of the overall scores for the importance of technique for performance and injury prevention on the technique proficiency scores, given the ordinal nature of the questionnaire data. The analysis was performed between the questionnaire responses and technique proficiency assessment scores for each individual technique and the overall scores, for tackling and ball-carrying. The level of significance was set at $\mathrm{p} \leq 0.05$. STATA V.13.0 (StataCorp LP, USA) was used for all statistical analyses. Data are reported as means and $95 \% \mathrm{CI}$, and Spearman's rank correlation coefficient $\left(\mathrm{r}_{\mathrm{s}}\right)$.

\section{Reliability}

To assess the intra-rater reliability of the analyst, five randomly selected players' tackles and ball-carries were analysed on two separate occasions. To assess the inter-rater reliability of the analyses, a second analyst, experienced with the criteria, assessed the same five players' tackles and ball-carries. Intra-rater and inter-rater reliability were calculated using the interclass correlation coefficient (ICC) and the typical error of measurement (TEM). ${ }^{41}$ The ICCs for both the intra-rater and the inter-rater tackle and ball-carry assessments were 1.0. The TEMs for the intra-rater tackle and ball-carry assessments were 0.7 and 0.5 arbitrary units (AU), respectively, and for the inter-rater, TEMs were 0.6 and 0.6 , respectively.

\section{RESULTS}

\section{Total technique scores}

The mean technical proficiency scores were 8.9 out of $16 \mathrm{AU}(95 \%$ CI 8.5 to 9.3$)$ and 9.3 out of $14(95 \%$ CI 8.9 to 9.7$)$ for tackling and ball-carrying, respectively. Ninety-six percent of players $(n=51 / 53)$ rated the importance of tackle technique to prevent injuries as somewhat important-very important. Similarly, $94 \%(\mathrm{n}=50 / 53)$ rated the importance of tackle technique to win the tackle contest as somewhat important to very important. For the ball carrier, $91 \%(\mathrm{n}=48 / 53)$ of players rated the importance of technique to prevent injuries as somewhat important-very important, and $92 \%(\mathrm{n}=49 / 53)$ rated the importance of technique to win the tackle contest as somewhat importantvery important. There was no significant relationship between a player's attitudes towards tackle or ball-carry technique for injury prevention and performance and his tackle or ball-carry technical proficiency score (figure 1).

\section{Specific technique scores}

The mean scores of the rated importance for each of the tackle and ball-carry techniques for injury prevention and performance were above 4 (somewhat important) (mean $\pm 95 \%$ CI range: $4.1 \pm 0.2-4.9 \pm 0.1$ ) except for the importance of the ball-carry technique side-on into contact

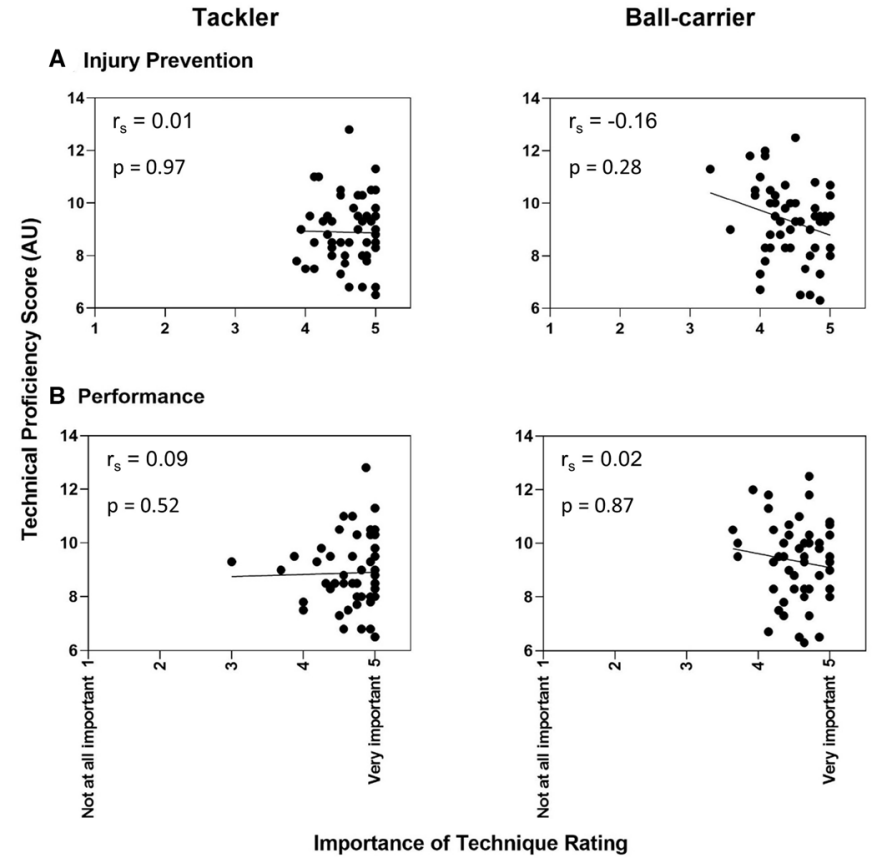

Figure 1 The relationship between tackler and ball-carrier technical proficiency scores, and the subjective importance of technique to prevent injury and to win the tackle contest. Lines represent line of best fit.

for injury prevention, which had a mean score of $3.9 \pm 0.2$ (undecided-somewhat important). For each individual tackle and ball-carry technique, the rated importance of each technique for injury prevention or performance was not related to a player executing the technique in the assessment ( $\mathrm{r}_{\mathrm{s}}$ range: -0.4 to 0.3 ).

\section{DISCUSSION}

Declarative awareness of safe and effective technique did not translate to execution of safe and effective technique

The purpose of this study was to determine the association between players' knowledge and attitudes towards safe and effective technique and their tackle and ballcarry technique execution. We found a high level of awareness among the players for the importance of technique to improve tackle performance and reduce tackle injury risks. This work supports previous research ${ }^{16-18}$ and highlights the effectiveness of a national injury prevention programme on increasing coaches' and players' knowledge of the importance of proper tackle technique. However, the knowledge of the importance of tackle and ball-carry technique did not translate to their tackle and ball-carry technique proficiency scores, respectively. This brings into question the effectiveness of this strategy alone on improving players' tackle technique. A similar question was raised in a systematic review of educational programmes to prevent concussions in rugby union. ${ }^{32}$ The review concluded that although educational programmes were effective in disseminating information to rugby union stakeholders, scant evidence was found on the education actually changing player behaviour towards concussion. ${ }^{32}$ Therefore, although 
disseminating educational material on safe and effective technique is adequate in improving declarative knowledge, it may not be sufficient on its own to reduce the tackle injury burden in rugby union.

\section{Gap between declarative and procedural knowledge may be the result of insufficient contact technique training}

The gap between players' declarative knowledge of proper tackle technique and their procedural knowledge of how to execute proper tackle techniques (reflected in their technical proficiency scores) is similar to a gap found in coaches' tackle knowledge and behaviours. ${ }^{18}$ In this study, coaches rated safe and effective technique as utmost important; however, this knowledge did not reflect on the amount of time they spent coaching tackle technique in training. ${ }^{18}$ Another study on the training volume of English professional rugby union over 11 seasons showed that only 24 min per player per week (out of an average of 6 hours $48 \mathrm{~min}$ per player per week of training) was spent in full contact sessions. ${ }^{33}$ The amount of time spent training the tackle, and the lack of association between knowledge of technique and actual technique found in this study, raises the question of whether the time spent on contact training is sufficient to allow players' declarative knowledge on safe and effective tackle technique to become procedural knowledge. One of the reasons given for the discrepancy between coaches' knowledge of the importance of technique and their training of tackle technique was that they did not feel confident in their ability to coach tackle technique. ${ }^{18}$ As a result, any full contact training sessions are likely to be less structured rather than technique focused. The dynamic environment of unstructured contact sessions exposes players to greater injury risks. ${ }^{33}$ Consequently, to protect their players, coaches may reduce the amount of time spent in full contact session, resulting in players not fully developing the technical components of their contact skills. Therefore, strategies that provide frameworks to equip players and coaches on how to train tackle technique safely may be more effective to improve tackle technique. ${ }^{3435}$

\section{Tackle technique training framework}

Strategies to develop tackle technique safely have been proposed. Hendricks and colleagues developed a 5-week tackle technique training framework. ${ }^{35}$ The framework draws from skill acquisition and development literature, and outlines how to progressively develop tackle technique proficiency through altering the conditions and coaching style of the sessions. ${ }^{35}$ Although more research is required to assess the efficacy of the tackle technique training programme, it serves as a potential tool to translate declarative knowledge to procedural knowledge, and ultimately improve tackle technique in training and matches.

\section{Limitations and future research recommendations}

This study sets out to describe the relationship between the knowledge of the importance of contact technique and contact technique proficiency. However, as most of the players in this study (over 90\%) reported both tackle and ball-carry technique to be important to improve performance and reduce injuries, the knowledge of players regarding the importance of tackle technique in this study was somewhat homogeneous. Therefore, rather than the relationship between ranges of tackle technique knowledge and proficiency, the results of this study may reflect the variance of tackle technique in players with a high level of knowledge of the importance of tackle technique. Further research may be warranted to describe the relationship between players with varying levels of knowledge and technique proficiency. However, as continuing endeavours ensue to improve the declarative knowledge of safe and effective technique in rugby union players, recruitment for such a study may be challenging. Also, it may be of interest to know players' perceptions of whether they are applying their tackle knowledge in training and matches. Although the tackle drill was designed to have a high degree of ecological validity and representativeness (phase before tackle, instructions to score or prevent the try, using rugby field demarcations), we acknowledge that the drill is only a simulated scenario of a match. With that said, the technical proficiency scores in the current drill are comparable with the scores recorded in matches. Burger et $a l,{ }^{4}$ using the same criteria, reported technical proficiency scores in elite U18 matches of 9.3 and 9.0 for the tackler and ball carrier, respectively. In comparison, the players in this cohort scored 8.9 and 9.3 for tackling and ball-carrying technique, respectively. This comparison highlights a potential avenue of research, that is, determining the relationship between the technique proficiency in training and in matches.

\section{CONCLUSION}

This is the first study to compare players' knowledge of the importance of proper tackle technique for injury prevention and performance with their tackle and ballcarry technique proficiency. Although there was a high level of awareness of the importance of technique to improve performance and promote safety, their knowledge was not related to their technique proficiency. The findings reveal a gap between players' knowledge of the importance of proper tackle technique and their execution of proper tackle technique,and support the need for contact skill training programmes in rugby union.

\section{Author affiliations}

${ }^{1}$ Division of Exercise Science and Sports Medicine, Department of Human Biology, University of Cape Town, Rondebosch, Western Cape, South Africa

${ }^{2}$ Western Province Rugby Academy, Cape Town, South Africa

${ }^{3}$ Health through Physical Activity, Lifestyle and Sport Research Centre (HPALS), Faculty of Health Sciences, University of Cape Town, Rondebosch, Western Cape, South Africa

${ }^{4}$ Carnegie Applied Rugby Research (CARR) Centre, Institute for Sport, Physical Activity and Leisure, Leeds Beckett University, Leeds, UK

${ }^{5}$ Leeds Rhinos Rugby League Club, Leeds, UK

${ }^{6}$ England Performance Unit, The Rugby Football League, Leeds, UK

${ }^{7}$ School of Science and Technology, University of New England, Armidale, New South Wales, Australia 
Twitter Steve den Hollander @steve_dh1, Mike Lambert @MikeLambert 01, Ben Jones@23benjones and Sharief Hendricks @Sharief_H

Contributors SdH was involved in the conception of the study, the data collection analysis and interpretation, drafted the article and approved the final version for publication. ML and BJ critically revised the article and approved the final version for publication. SH was involved in the conception of the study, the data analysis and interpretation, critically revised the article and approved the final version for publication.

Funding The authors would like to acknowledge the National Research Foundation of South Africa for support during the study.

Competing interests None declared.

Patient consent for publication Not required.

Ethics approval This study was approved by the University of Cape Town Human Research Ethics Committee, HREC778/2017.

Provenance and peer review Not commissioned; externally peer reviewed.

Data availability statement Data are deidentified participant data, and are available upon request from the corresponding author.

Open access This is an open access article distributed in accordance with the Creative Commons Attribution Non Commercial (CC BY-NC 4.0) license, which permits others to distribute, remix, adapt, build upon this work non-commercially, and license their derivative works on different terms, provided the original work is properly cited, appropriate credit is given, any changes made indicated, and the use is non-commercial. See: http://creativecommons.org/licenses/by-nc/4.0/.

\section{ORCID iDs}

Steve den Hollander http://orcid.org/0000-0002-6064-038X

Sharief Hendricks http://orcid.org/0000-0002-3416-6266

\section{REFERENCES}

1 Roberts SP, Trewartha G, England M, et al. Collapsed scrums and collision tackles: what is the injury risk? $\mathrm{Br} J$ Sports Med 2015;49:536-40.

2 Higham DG, Hopkins WG, Pyne DB, et al. Relationships between rugby sevens performance indicators and international tournament outcomes. J Quant Anal Sports 2014;10.

3 Cruz-Ferreira A, Cruz-Ferreira E, Santiago L, et al. Epidemiology of injuries in senior male rugby Union sevens: a systematic review. Phys Sportsmed 2017;45:41-8.

4 Burger N, Lambert MI, Viljoen W, et al. Tackle technique and tacklerelated injuries in high-level South African rugby Union under-18 players: real-match video analysis. Br J Sports Med 2016;50:932-8.

5 Bahr R, Holme I. Risk factors for sports injuries--a methodological approach. Br J Sports Med 2003;37:384-92.

6 Hendricks S, O'connor S, Lambert M, et al. Contact technique and concussions in the South African under-18 Coca-Cola Craven week rugby tournament. Eur J Sport Sci 2015;15:557-64.

7 Tierney GJ, Denvir K, Farrell G, et al. The effect of technique on tackle gainline success outcomes in elite level rugby Union. Int $J$ Sports Sci Coach 2018;13:16-25.

8 Hendricks S, Matthews B, Roode B, et al. Tackler characteristics associated with tackle performance in rugby Union. Eur J Sport Sci 2014;14:753-62.

9 Tucker R, Raftery M, Verhagen E. Injury risk and a tackle ban in youth rugby Union: reviewing the evidence and searching for targeted, effective interventions. A critical review. Br J Sports Med 2016;50:921-5.

10 Finch C. A new framework for research leading to sports injury prevention. J Sci Med Sport 2006;9:3-9.

11 Hendricks S, Lambert M. Tackling in rugby: coaching strategies for effective technique and injury prevention. Int J Sports Sci Coach 2010;5:117-35.

12 Posthumus M, Viljoen W. BokSmart: safe and effective techniques in rugby Union. S Afr J Sports Med 2008;20:64-70.

$13 \mathrm{Kim}$ JW, Ritter FE, Koubek RJ. An integrated theory for improved skill acquisition and retention in the three stages of learning. Theor Issues Ergon Sci 2013;14:22-37.
14 Thomas KT, Thomas JR. Developing expertise in sport: the relation of knowledge and performance. Int J Sport Psychol 1994;25:295-312.

15 Steenbergen B, van der Kamp J, Verneau M, et al. Implicit and explicit learning: applications from basic research to sports for individuals with impaired movement dynamics. Disabil Rehabil 2010;32:1509-16.

16 Hendricks S, Sarembock M. Attitudes and behaviours of toplevel junior rugby Union coaches towards the coaching of proper contact technique in the tackle - a pilot study. S Afr J Sports Med 2013;25:8.

17 Hendricks S, Jordaan E, Lambert M. Attitude and behaviour of junior rugby union players towards tackling during training and match play. Saf Sci 2012;50:266-84.

18 Hendricks S, Sarembock M, Jones B, et al. The tackle in South African youth rugby union - Gap between coaches' knowledge and training behaviour. Int J Sports Sci Coach 2017;12:708-15.

19 Hendricks S, Till K, den Hollander S, et al. Consensus on a video analysis framework of descriptors and definitions by the rugby Union video analysis consensus group. $\mathrm{Br} J$ Sports Med 2020;54:566-72

20 Otte FW, Millar S-K, Klatt S. Skill training periodization in "Specialist" sports coaching -An introduction of the "PoST" framework for skill development. Front Sports Act Living 2019;1:61.

21 Hendricks S, den Hollander S, Tam N, et al. The relationships between rugby players' tackle training attitudes and behaviour and their match tackle attitudes and behaviour. BMJ Open Sport Exerc Med 2015;1:e000046.

22 Gabbett T, Ryan P, technique T. Tackling technique, injury risk, and playing performance in high-performance collision sport athletes. Int J Sports Sci Coach 2009;4:521-33.

23 Speranza MJA, Gabbett TJ, Greene DA, et al. An alternative test of tackling ability in rugby League players. Int J Sports Physiol Perform 2018;13:347-52.

24 den Hollander S, Lambert M, Jones B, et al. Tackle and ruck technique proficiency within Academy and senior Club rugby Union. J Sports Sci 2019;37:2578-87.

25 Gabbett TJ, Jenkins DG, Abernethy B. Relationships between physiological, anthropometric, and skill qualities and playing performance in professional rugby League players. J Sports Sci 2011;29:1655-64.

26 Speranza MJ, Gabbett TJ, Johnston RD, et al. Relationship between a standardized tackling proficiency test and match-play tackle performance in semiprofessional rugby League players. Int J Sports Physiol Perform 2015;10:754-60.

27 Speranza MJA, Gabbett TJ, Greene DA, et al. Relationship between 2 standardized tackling proficiency tests and rugby League Match-Play tackle performance. Int J Sports Physiol Perform 2018;13:770-6.

28 Gabbett T, Kelly J, Pezet T. Relationship between physical fitness and playing ability in rugby League players. J Strength Cond Res 2007;21:1126-33.

29 Hendricks S, den Hollander S, Lambert M. Coaching behaviours and learning resources; influence on rugby players' attitudes towards injury prevention and performance in the tackle. Sci Med Football 2019:1-5

30 Blair J, Czaja RF, Blair EA. Designing surveys: a guide to decisions and procedures. Thousand Oaks, California: Sage Publications, 2013.

31 Hopkins WG, Marshall SW, Batterham AM, et al. Progressive statistics for studies in sports medicine and exercise science. Med Sci Sports Exerc 2009;41:3-12.

32 Fraas MR, Burchiel J. A systematic review of education programmes to prevent concussion in rugby Union. Eur J Sport Sci 2016;16:1212-8.

33 West SW, Williams S, Kemp SPT, et al. Patterns of training volume and injury risk in elite rugby Union: an analysis of 1.5 million hours of training exposure over eleven seasons. J Sports $\mathrm{Sci}$ 2020;38:238-47.

34 Hendricks S, Till K, Brown JC, et al. Rugby Union needs a contact skill-training programme. Br J Sports Med 2017;51:829-30.

35 Hendricks S, Till K, Oliver JL, et al. Technical skill training framework and skill load measurements for the rugby Union tackle. Strength Cond J 2018;40:44-59. 